\title{
Recombinant Thymosin
}

National Cancer Institute

\section{Source}

National Cancer Institute. Recombinant Thymosin. NCI Thesaurus. Code C883.

A recombinant form of a polypeptide chemically identical to or similar to the hormone secreted by the thymus gland. Thymosin is generally known to have functions in the preprocessing of $\mathrm{T}$ cells and the development of B cells to plasma cells to produce antibodies. In particular, the predominant form of thymosin, beta 4 thymosin, is the principal actin-sequestering protein that plays an important role in functions that involve actin molecules, such as maintenance of cell shape, cytoplasmic organization, cell movement, and cell division. 